\title{
Comprehensive Two-Dimensional Gas Chromatography Coupled to Time-of-Flight Mass Spectrometry in Human Metabolomics
}

\author{
Petr Wojtowicz ${ }^{1, *}$, Jitka Zrostlíková2, Veronika Št'astná1, \\ Eva Dostálová1, Lenka Žídková1, Per Bruheim ${ }^{3}$ and Tomáš Adam1,, \\ ${ }^{1}$ Laboratory for Inherited Metabolic Disorders $\mathcal{E}$ Institute of Molecular and \\ Translational Medicine, Palacký University in Olomouc, \\ ${ }^{2}$ LECO Application Laboratory, Prague, \\ ${ }^{3}$ Department of Biotechnology, NTNU, Trondheim, \\ ${ }_{1,2}$ Czech Republic \\ ${ }^{3}$ Norway
}

\section{Introduction}

Metabolomics is a discipline aiming to characterize a phenotype by means of metabolome analysis. In recent years, it has developed into an accepted and valuable tool in life sciences and its use has been growing rapidly in the study of microbial, plant, and mammalian metabolomes. It has been shown to be an effective tool in characterizing cancer cells and their response to anticancer drugs (Griffiths \& Chung, 2008). To assess the effects of drugs on important pathways in clinical trials of innovative therapies, metabolomic approaches might be more cost-effective than those that measure specific molecular targets (Workman et al., 2006). The derived biomarkers applied in early clinical trials are expected to help identify appropriate patients, provide proofs of concepts, aid decision making, and ultimately reduce the high level of attrition and costs of drug development (Sarker \& Workman, 2007).

The biological specimens used in human metabolomic studies are e.g. urine (Weiss et al., 2007), blood plasma (Boernsen et al., 2005), and saliva (Walsh et al., 2006). All of them can play an important role in the diagnostic processes of problem illnesses. The individual metabolome of human biofluids is defined by genetic factors but it can also be affected by diet, age, disease, etc. In this respect, the use of human cell cultures offers a good alternative, since the influence of the above-mentioned factors is minimized in a culture where a defined extracellular environment takes place (Rabinowitz et al., 2006).

As concerns the analytical techniques applied in metabololmics, chromatographic techniques coupled to mass spectrometry play an important role. For the analysis of organic acids, amino acids, and sugars gas chromatography-mass spectrometry (GC-MS) after derivatization is widely applied. Since biological materials represent a very complex matrix,

* Authors equally contributed to the work 
classical GC-MS techniques can struggle with the high number of components present and the occurring co-elutions. In this respect, comprehensive two-dimensional gas chromatography $(\mathrm{GC} \times \mathrm{GC})$ brings significant benefits and its coupling with time-of-flight mass spectrometry (GC $\times$ GC-TOF-MS) has become an emerging technique in this field (Koek et al., 2011).

Due to a polar nature of target compounds, derivatization procedure is required for GC-MS analysis. Although silylation is the most widely used approach, it has certain limitations such as formation of more products from a single analyte. Moreover, the ratios between individual silylated products can change with time. To overcome these drawbacks, other derivatization procedures such as indirect alkylation via chloroformates or acylation have been used (Husek \& Simek, 2006).

This contribution is focused on the application of comprehensive two-dimensional gas chromatography coupled to time-of-flight mass spectrometry for the analysis of human biological materials (urine, plasma, and cultured skin fibroblasts) in relation to diagnosing metabolic disorders, cell metabolism quenching, and drug metabolomic impact prediction.

\section{Comprehensive two-dimensional gas chromatography}

\subsection{Basic theory}

Comprehensive two-dimensional gas chromatography (GC $\times$ GC) is a technique utilizing two columns of different selectivity connected in series by the modulation device. The modulator cuts slices from the first-dimension column effluent and re-injects them to the secondary column. Due to the difference in column polarity, each simple compound is subjected to two independent separation mechanisms. Compared to one-dimensional GC, this technique brings dramatically increased peak capacity, improved peak resolution, and up to an order of magnitude increase in compounds' detectability. In contrary to heart-cutting variety, in GC $\times$ GC all effluent from the primary column passes through the secondary column, maximizing sample resolution throughout the entire analysis (Gorecki \& Harynuk, 2004; Beans \& Brinkman, 2005). A theoretical and practical comparison of one-dimensional GC and GC × GC in terms of peak capacity has been published by Blumberg et al., 2008.

In GC $\times$ GC, two basic orthogonality rules should be kept: (i) independence of separation mechanisms, i.e. the two columns should possess of different selectivity; (ii) preserving of the first-dimension separation, i.e. the peaks already separated on the first column must not be mixed-up in the modulator. For this reason, the modulation must occur at frequency of at least 3-5 modulations per first dimension peak. But in practice, the full independence is not possible, so in the case of GC $\times$ GC this must be considered as the degree of GC $\times$ GC system orthogonality, or "relative" or "partial" orthogonality which can be characterized by the percent usage of the available separation space (Ryan et al., 2005; Zhu, 2009).

\subsection{Technical aspects}

GC $\times$ GC occurs by the subsequent re-injection of effluent from one chromatographic column into the second "orthogonal" column. As already mentioned, a minimum number of modulations per first dimension peak are required to maintain the first dimension separation which typically results in modulation periods of 1-5 s. A flash separation on the 
second dimension column has to be completed before the next modulation cycle starts. In this way, the separation obtained in the first dimension is preserved and additional separation on the second column is obtained. The re-injection process is called modulation and is enabled by an interface device called modulator, often referred to as the "heart" of the system. A GC $\times$ GC modulating interface can be placed at the end of the first dimension ( $\left.{ }^{1} \mathrm{D}\right)$ or at the beginning of the second dimension ( $\left.{ }^{2} \mathrm{D}\right)$, e.g. for thermal modulators, or between the columns (valve-based modulators). Nowadays, cryo-modulators which trap primary column effluent below ambient temperatures with the use of various cooling mechanisms are most commonly used (Edwards et al., 2011).

As a typical column set-up, a nonpolar column is used as the ${ }^{1} \mathrm{D}$ and polar one in the ${ }^{2} \mathrm{D}$. Under these conditions, separation according to the volatility of the compounds occurs in the 1D column while "polarity" separation dominates in the ${ }^{2} \mathrm{D}$ column. In principle, the column arrangement can be inverted. Both set-ups have their advantages and disadvantages and therefore the right set-up must be a result of optimization of a particular application. As concerns the column dimension, the first column is relatively long (typically 30-60 m) and normal bore (typically $0.25 \mathrm{~mm}$ with $0.25 \mu \mathrm{m}$ film thickness). The second column has to be very short and narrow (typically $1-2 \mathrm{~m}$ of a $0.1 \mathrm{~mm}$ column with $0.1 \mu \mathrm{m}$ film thickness) to perform a very fast separation. The use of such narrow-bore column results in limited sample capacity and easy 2D column overloading, especially for biological samples. This limitation has been overcome by the use of wider-bore columns in the second dimension (Koek et al., 2008).

Primary GC $\times$ GC data are a series of second dimension chromatograms registered by the detector. Appropriate software reconstructs the second dimension chromatograms into three-dimensional plots or contour plots as shown in Figure 1.

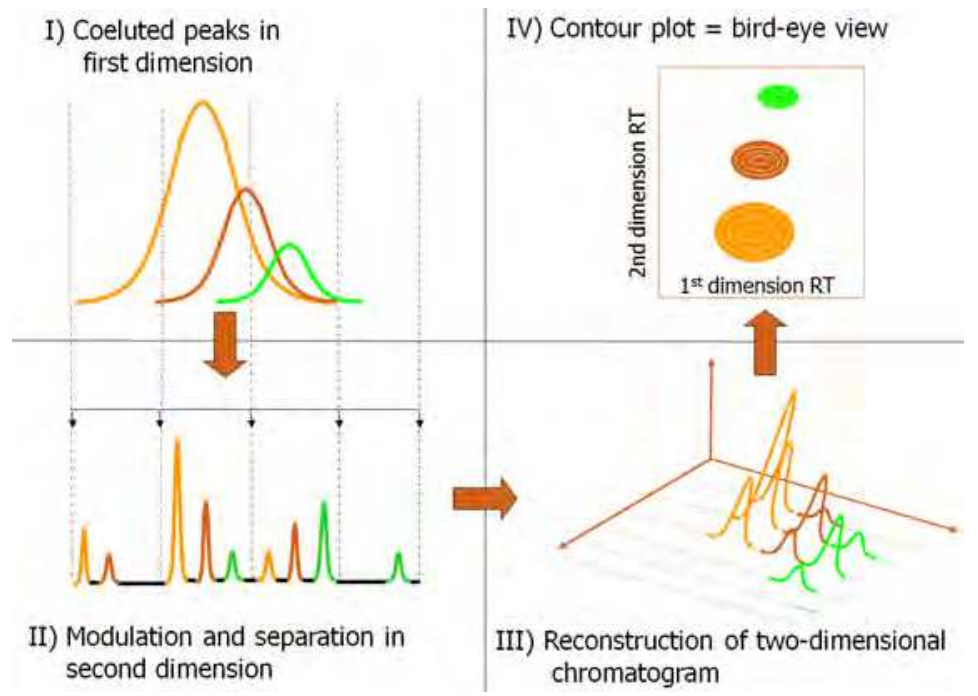

Fig. 1. Construction of a contour plot. The ${ }^{1} \mathrm{D}$ effluent containing not fully separated analytes is modulated to create a series of short ${ }^{2} \mathrm{D}$ chromatograms. They are reconstructed by the software form a three-dimensional view. For the practical purposes the contour plot view is more feasible. 
As concerns the detectors applicable in GC $\times$ GC, the peak width generated by this technique must be taken into account. Typical GC $\times$ GC peaks are $0.1-0.3 \mathrm{~s}$ wide, thus to get a sufficient number of data points to accurately describe the shape of the peak (at least 10 points per peak) a detector must collect data at a rate of at least $100 \mathrm{~Hz}$. For the coupling of GC $\times$ GC with MS detection, a high-speed TOF-MS is the technique of choice in most studies. Quadrupole MS have been also applied in GC × GC (Adahchour et al., 2006) with some compromises in the data density and mass range.

Since GC $\times$ GC generates large quantities of data, appropriate software tools become very important, not only for data acquisition but also visualization and interpretation. Depending on the data itself, various operations may be required, typically including background removal, mass spectral deconvolution, peak finding, combination of modulated peaks, peak height (area, or other characteristics) computation, identification of the found peaks by the comparison with mass spectral databases (or custom libraries), and finally export of analysis report (Reichenbach et al., 2004).

\subsection{Application of GC $\times$ GC and its current trends}

Since its introduction in 1991 (Liu \& Philips, 1991), the GC $\times$ GC technique has gone through the years of rapid development. Today, GC $\times$ GC is widely used in many diverse areas which cover an interesting variety of applications. In general, the usage possibilities of GC $\times$ GC can be divided into three areas - fingerprints of very complex matrices, target analyses, and identification of unknown compounds. An excellent review on the GC $\times$ GC applications written by Adahchour et al. maps the usage of the technique from its introduction till 2008 in following fields - petrochemical products, environmental studies (soils and sediments, airs and aerosols, cigarette smoke), organohalogen compounds, food analysis (fats and oils, essential oils, alcoholic beverages), and also biological samples (Adahchour et al., 2008).

A significant progress can be noted in biosciences applications. In the field of human metabolomics, it covers e.g. metabolomic profiling of infant urine (Kouremenos et al., 2010; Wojtowicz et al., 2010), biomarker discovery of diabetes mellitus (Li et al, 2009), defining the "metabolome" of psychical disorders like schizophrenia (Oresic et al., 2011), sterol analysis (Mitrevski et al., 2008), analyses of tumorogenic cells (Paskanti et al., 2010), identification of anabolic agents in doping control (Mitrevski et al., 2010), or enatioselective analyses (Wadhier et al., 2011).

As regards the recent developments in GC $\times$ GC, the utilization of new stationary phases such as ionic liquids (Zapadlo et al., 2011), development of new modulators, e.g. (Panic et al., 2011), and improvement of data handling and evaluation (Wang et al., 2010; Kim et al., 2011; Koek et al., 2011) should be mentioned.

\section{Derivatization via chloroformates}

Analytes derivatization is employed in many analytical methods that utilize GC as a final step. The dominant reasons for derivatization in GC are either to increase analytes volatility, to improve their chromatographic behaviour by decreasing of polarity or to increase the detector sensitivity of the target analytes. The group of silylation procedures is by far the dominant derivatization methods. Silylation is almost universal technique and the silyl groups increase the total ion current which leads to increase the sensitivity using positive ion MS (Wells, 1999). 
On the other hand, this derivatization procedure has several disadvantages. First, it is timeconsuming and requires elevated temperature. Further, the silylation reactions result in the formation of many artifacts as well as forming of multiple peaks for the same compound or the presence of unexpected peaks in the chromatogram. Also, in the electron impact mass spectra of silylated compounds, the non-specific masses belonging to the silyl group prevail, while the molecular and other characteristic ions have low intensity, which complicates spectra interpretation. Finally, it is also important to mention the instability of the silylated compounds and its sensitivity even to the traces of moisture which makes sample preparation and storage more demanding (Little, 1999; Ong et al., 2010).

As a promising alternative derivatization technique, an indirect alkylation via chloroformates appears. The sample preparation procedure is as follows. A portion of pyridine (serving as a catalyst) and an alcohol (to form esters) is added to the sample that is present in basic-aqueous environment. The reaction itself starts with the addition of an appropriate alkyl chloroformate. The reaction is fast (seconds) and no heating is needed. An illustration of derivatization reaction is shown in Figure 2. After the reaction, the derivates are directly extracted into the water-immiscible organic solvent (chloroform, isooctane) that can be immediately (or after drying by e.g. anhydrous sodium sulfate) injected. In this way a biological material (plasma, urine, cell extract) can be derivatized without any pretreatment.

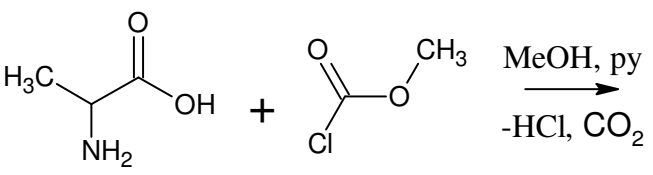<smiles>COC(=O)NC(C)C(=O)OC</smiles>

Fig. 2. Derivatization method using methyl chloroformate (MCF). 2-Aminopropanoic acid (alanine) is converted to methyl 2-[(methoxycarbonyl)amino]propanoate

Using this procedure, due to the reaction conditions ( $\mathrm{pH}$, presence of other solvents), many polar-functional groups are converted to the corresponding forms, i.e. - carboxy, amino, hydroxyl, and thiol groups to esters, carbamates, carbonates, and thiocarbonates, respectively. The reactions are robust with low-cost reagents and in majority cases (>95\%) produce a single stable derivate that has an easily interpretable MS spectrum (Figure 3).

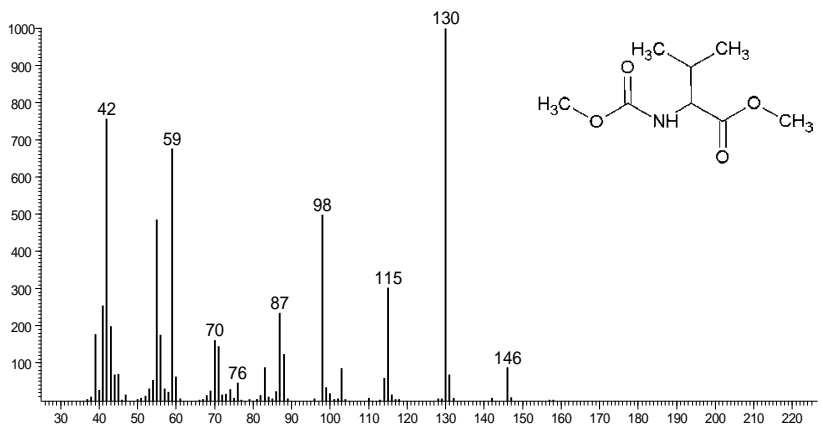

Fig. 3. MS spectrum of MCF derivate of valine 


\section{Material and methods}

\subsection{Chemicals and reagents}

Internal standards (4-phenylbutyric acid for TMS, norvaline for MCF), ethoxyamine hydrochloride, methanol (HPLC grade), pyridine (p.a.), methyl-chloroformate (MCF, 99\%, for GC), chloroform ( $\geq 99.9 \%$, for HPLC), trypsin/EDTA (10×), N-methyl-Ntrimethylsilyltrifluoroacetamide (MSTFA), containing $1 \%$ of trimethylchlorosilane, Dulbecco's Modified Eagle's Medium, and amphotericin were purchased from SigmaAldrich (St. Louis, USA). Fetal bovine serum was from PANBiotech (Aidenbach, Germany), sodium chloride solution (0.9\%) from B Braun (Melsungen, Germany). Other chemicals for sample preparation, i.e. hydrochloric acid, sodium chloride, sodium hydroxide, anhydrous sodium sulfate, sodium bicarbonate, ethyl acetate (p.a.), and acetone (p.a.) were supplied by LACH-NER (Neratovice, Czech Republic). 5-Fluorouracil (250 mg in $5 \mathrm{~mL}$ ) was from EBEWE Pharma (Unterach, Austria). Standard mixture of 32 amino acids and dipeptides $(200 \mu \mathrm{mol} / \mathrm{L})$ was from the EZfaast kit (Phenomenex, USA). All chemicals and reagents were of analytical grade or higher.

\subsection{Samples and their preparation}

\subsubsection{Urine samples}

For the analysis of organic acids, urine samples were acidic-extracted into ethyl acetate, ethoxymated and silylated by MSTFA. We analyzed 10 healthy urines and urines from patients with inherited metabolic disorder. For more detail see (Wojtowicz et al., 2010).

Analytes response was normalized to the concentration of creatinine measured by the common Jaffe rate method.

\subsubsection{Fibroblasts}

Human skin fibroblasts were cultured by standard protocol (Dulbecco's Modified Eagle's Medium, supplemented with $10 \%$ of fetal bovine serum and amphotericin $100 \mu \mathrm{g} / \mathrm{mL}$, $37^{\circ} \mathrm{C}, 5 \% \mathrm{CO}_{2}, 25 \mathrm{~cm}^{2}$ flasks) to confluence. The cells were harvested by quenching or trypsinization (see below).

Quenchinq procedure: The cells were quenched by spraying-out of $20 \mathrm{~mL}$ of $60 \%$ aqueous methanol (v/v) pre-cooled to $-50^{\circ} \mathrm{C}$ using plastic syringe with bent needle. The flasks with quenched cells were kept on dry ice and the cells were extracted with $1 \mathrm{~mL}$ of cold $\left(-50{ }^{\circ} \mathrm{C}\right)$ methanol solution $(80 \%, \mathrm{v} / \mathrm{v})$ while scraping. The cell debris in the methanol solution was drained out with pipette and another $1 \mathrm{~mL}$ of cold extraction solution to wash the flask was used. Both methanol fractions were combined, sonicated $(1 \mathrm{~min})$, and centrifuged $(1800 \mathrm{~g}$, $5 \mathrm{~min}$ ) to remove the cell pellet and the supernatant was freeze-dried, silylated or alkylated via MCF. For the experiment with 5-fluorouracil (5-FU), the growing medium was supplemented with the drug $(50 \mu \mathrm{mol} / \mathrm{L})$ for 6,24 , and 48 hours before quenching procedure, respectively.

Trypsinization: Before trypsinization the cells were washed twice with $0.9 \%$ sodium chloride solution and then the trypsin/EDTA solution was added. After 2 min, trypsin was deactivated by adding of $5 \mathrm{~mL}$ of a cultivation medium. The cell suspension was centrifuged 
( $260 \mathrm{~g}, 5 \mathrm{~min})$ and the pellet was extracted twice by $1 \mathrm{~mL}$ of $80 \%$ methanol. Combine extracts were freeze-dried.

Freeze-dried intracellular metabolite extracts were derivatized for analysis by two-stage silylation procedure based on the method described previously (Koek et al., 2006). The dry extracts were derivatized with ethoxyamine hydrochloride $(10 \mu \mathrm{L}, 56 \mathrm{mg} / \mathrm{mL}$ in pyridine) and $20 \mu \mathrm{L}$ of pyridine for $60 \mathrm{~min}$ at $40^{\circ} \mathrm{C}$. Subsequently, the extracts were silylated for $50 \mathrm{~min}$ at $40^{\circ} \mathrm{C}$ with $40 \mu \mathrm{L}$ of MSTFA and $30 \mu \mathrm{L}$ of pyridine.

The MCF derivatization was as follows: Dry metabolite extract was dissolved in $100 \mu \mathrm{L}$ of water and $200 \mu \mathrm{L}$ of sodium hydroxide $(0.5 \mathrm{~mol} / \mathrm{L})$. The mixture was transferred into the glass tube containing $20 \mu \mathrm{L}$ of internal standard norvaline $(0.1 \mathrm{mmol} / \mathrm{L})$. After, $200 \mu \mathrm{L}$ of methanol and $50 \mu \mathrm{L}$ of pyridine as a catalyst were added and the mixture was briefly vortexed. The derivatization reaction was started by adding $20 \mu \mathrm{L}$ of MCF and the mixture was then vortexed for $30 \mathrm{~s}$. Another $20 \mu \mathrm{L}$ portion of MCF was added again followed by shaking for $30 \mathrm{~s}$. To separate the MCF derivatives from the reactive mixture a $300 \mu \mathrm{L}$ of chloroform was added and shaken $10 \mathrm{~s}$ followed by the addition of $300 \mu \mathrm{L}$ of sodium bicarbonate solution $(50 \mathrm{mmol} / \mathrm{L})$ and shaking for an additional $10 \mathrm{~s}$. For better layering, the tubes were centrifuged $(1000 \mathrm{~g}, 1 \mathrm{~min})$. The upper aqueous layer was discarded and the chloroform phase was dried by adding a small portion of anhydrous sodium sulfate. The dry organic solution was transferred to a GC vial with an insert which was tightly capped and then analyzed.

\subsubsection{Plasma samples}

The control and patient plasma samples were from infants from routine diagnostic processes performed in the laboratory of authors. The diagnoses had been previously confirmed by biochemical, enzyme or molecular-genetic analyses in all the patients. We analyzed 10 control samples and 19 samples with amino acids defects (phenylketonuria, PKU, maple syrup urine disease, MSUD, tyrosinemia I, TYR I, homocystinuria, HCYS, carbamoyl phosphate synthetase deficiency, CPS, ornithine transcarbamylase deficiency, OTC, and non-ketotic hyperglycinemia, NKH) (Janeckova et al., 2011).

For the MCF derivatization procedure, $50 \mu \mathrm{L}$ of plasma were pipetted into the glass tube containing $20 \mu \mathrm{L}$ of internal standard norvaline $(0.1 \mathrm{mmol} / \mathrm{L})$. After addition of $200 \mu \mathrm{L}$ of sodium hydroxide $(0.5 \mathrm{~mol} / \mathrm{L})$, the derivatization procedure was the same as in the case of fibroblasts.

\subsection{Optimized analyses conditions}

A Pegasus 4D system consisting of an Agilent 7890A gas chromatograph (Agilent Technologies, Palo Alto, USA), a MPS2/CIS4/ALEX system (Gerstel, Mülheim an der Ruhr, Germany), and a Pegasus HT time-of-flight mass spectrometer (LECO Corporation, St. Joseph, USA) was used. The GC $\times$ GC system employed a dual-stage, quad-jet modulator and a secondary oven, both built-in to the Agilent GC oven. A consumable-free option of the modulator was employed. Compressed air was used for both hot and cold modulation jets. For the hot jets the air was resistively heated, while for the cold jets the air passed through a moisture filter and was cooled by immersion cooling $\left(-80^{\circ} \mathrm{C}\right)$. 
The nonpolar/polar (BPX5, $30 \mathrm{~m} \times 0.25 \mathrm{~mm} \times 0.25 \mu \mathrm{m} \&$ BPX50, $2.0 \mathrm{~m} \times 0.1 \mathrm{~mm} \times 0.1 \mu \mathrm{m}$, both Supelco) column arrangement with a modulation on the first column was chosen. The columns were connected using a SilTite Mini Union (SGE, Ringwood, Australia). The oven temperature program differs due to the derivatization procedure - TMS: primary oven temperature: $40^{\circ} \mathrm{C}(2 \mathrm{~min}), 8^{\circ} \mathrm{C} / \mathrm{min}$ to $155^{\circ} \mathrm{C}(0.2 \mathrm{~min}), 10^{\circ} \mathrm{C} / \mathrm{min}$ to $255^{\circ} \mathrm{C}(0.20 \mathrm{~min})$, and isocratically $300^{\circ} \mathrm{C}(5 \mathrm{~min})$; secondary oven temperature: $+5^{\circ} \mathrm{C}$ above the primary oven temperature; modulator temperature: $+50^{\circ} \mathrm{C}$ above the primary oven temperature; modulation period: $3 \mathrm{~s}$ (hot pulse $0.6 \mathrm{~s}$ ), solvent delay $650 \mathrm{~s}$; MCF: $60^{\circ} \mathrm{C}(1.5 \mathrm{~min})$, $15^{\circ} \mathrm{C} / \mathrm{min}, 300^{\circ} \mathrm{C}(5 \mathrm{~min})$, secondary oven temperature: $+10^{\circ} \mathrm{C}$ above the primary oven temperature; modulator temperature: $+30^{\circ} \mathrm{C}$ above the primary oven temperature; modulation period: $4 \mathrm{~s}$ (hot pulse $0.8 \mathrm{~s}$ ), solvent delay $300 \mathrm{~s}$.

Other conditions were as follows:: carrier gas: helium at the corrected constant flow $1 \mathrm{~mL} / \mathrm{min}$; splitless injection $\left(1 \mathrm{~min}, 250{ }^{\circ} \mathrm{C}\right), 0.2-1 \mu \mathrm{L}$ due to the application; TOF-MS: electron ionization $(-70 \mathrm{eV})$; ion source temperature: $250^{\circ} \mathrm{C}$; acquired mass range: $\mathrm{m} / \mathrm{z} 35$ 550; acquisition rate: 100 spectra/s; detector voltage: $-1500 \mathrm{~V}$; transfer line temperature: $250{ }^{\circ} \mathrm{C}$.

ChromaTOF software v. 4.24 (LECO Corporation, USA) was used for system control, data acquisition, and data processing. The NIST/EPA/NIH Mass Spectral Library (2008) was used for tentative identification of compounds, with confirmations by retention indices comparisons. System Gerstel was controlled by Maestro software v. 1.3 (Mülheim an der Ruhr, Germany).

\subsection{Data processing and quantification}

An automated data processing based on the so called "Reference" was performed by the ChromaTOF software. The analyte concentration was calculated from the deconvoluted total ion current (DTIC) peak area.

Multivariate statistical data analyses (Principal Component Analysis - PCA, Hierarchical Cluster Analysis - CA) were performed using Statistica 8.0 (www.statsoft.com). A heat-map was created using the Cluster v. 3.0 software (http://bonsai.hgc.jp) and visualized by the TreeView v. 1.1.5 software (http://jtreeview.sourceforge.net).

\subsubsection{Deconvoluted total ion current}

Reference materials of rarely occurring pathological metabolites are not always easily available and/or their cost is considerably high. Therefore, it is a common practice to use the total ion chromatogram (TIC) signal for quantification along with the internal standard use. This approach was used also in this work. However, TIC quantification can overestimated results in case of chromatographic coelutions, which cannot be completely avoided even with GC × GC.

This obstacle was overcome in our work by using deconvoluted total ion chromatogram (DTIC) for the quantification of the analytes. Deconvolution is a mathematical algorithm that is based on the absence of spectral skew and faster acquisition rates for peak apex definition in TOF-MS data. This algorithm mathematically separates mass spectra of compounds that chromatographically co-elute. In addition to producing deconvoluted 
spectra, the ChromaTOF software also allows the calculation of DTIC peak area. Deconvoluted TIC is the portion of TIC area corresponding to a particular analyte in a coelution. An example is shown in Figure 4.
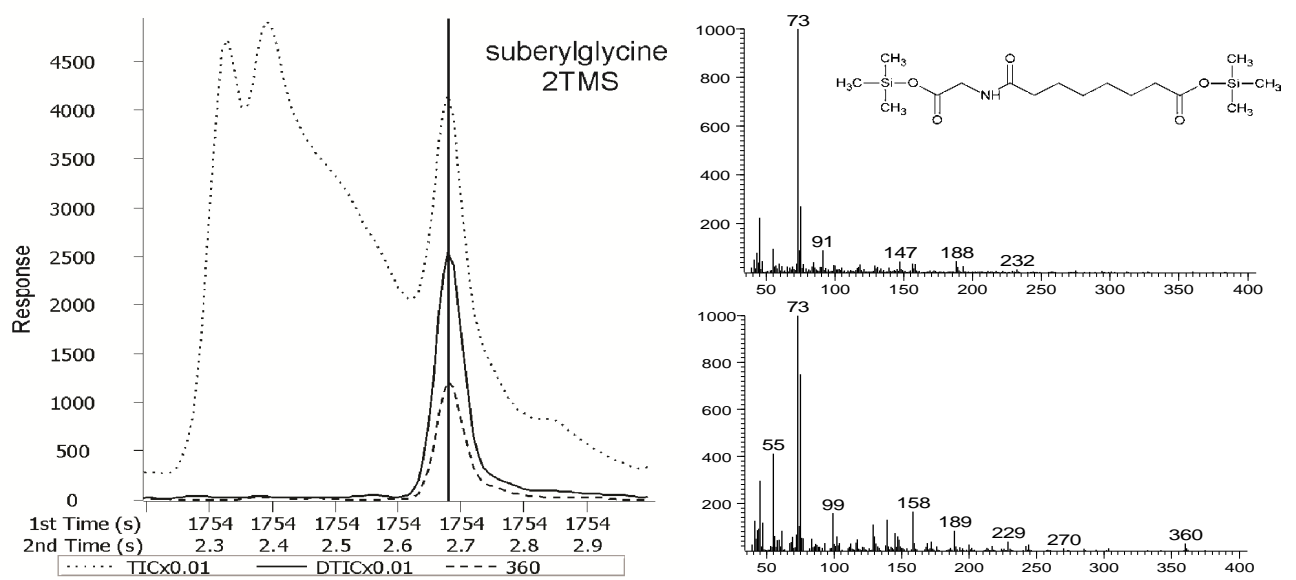

Fig. 4. Creation of DTIC for suberylglycine 2TMS (analysis of urine extract). On the right the raw peak apex spectrum (up) and the spectrum after deconvolution (down) are shown. The similarity between the deconvoluted spectra and the spectra from the library was 895 .

\subsubsection{Using the reference}

When a classical GC-MS is used, the chromatogram is typically reviewed manually by plotting characteristic masses in the segment of the expected retention time. To avoid such a time-consuming procedure, a ChromaTOF feature called "Reference" was applied. This procedure consisted of the following steps:

i. $\quad$ The sample is processed using a general peak finding method (e.g. S/N 200).

ii. Peaks of interest are exported to the Reference, which is a set of information containing the retention times and mass spectrum of each analyte, among other data. Criteria such as the retention time window-width in both dimensions and minimum spectral match are defined by the user.

iii. The Reference is applied to target search for each analyte in the unknown sample and for the quantification of positively identified analytes.

iv. If some new interesting analyte is found in newly processed sample, it can be added to the existing Reference.

The retention time tolerances were determined based on the repeatability of retention times. The appropriate relative standard deviations $(n=10)$ of the retention times of selected urine metabolites were under $0.17 \%$ and $1.74 \%$ for ${ }^{1} \mathrm{D}$ and ${ }^{2} \mathrm{D}$, respectively (Wojtowicz et al., 2010).

Using this approach, two References have been made - one for TMS and one for MCF-based derivatization which will be described in following sections. 


\section{Results and discussion}

\subsection{Analysis of samples derivatized by silylation}

EZfaast standard solution (contains 32 amino acids and dipeptides), 10 healthy and 14 pathological urine extracts, and 15 quenched fibroblast extracts derivatized by TMS were analyzed by a GC $\times$ GC-TOF-MS method and subjected to data processing procedure. After manual inspection of these peaks and confirmation of their identity by means of retention indices, a Reference was created from these compounds. This TMS compounds Reference contains 268 analytes at this moment.

The analyzed compounds are organic acids (e.g. suberate, malonate, palmitate) and their derivates (e.g. 2-oxoisovalerate, lactate, vanillylmandelate, mevalonolactone), amino acids (e.g. glycine, valine, phenylalanine) and their derivates (e.g. 3,4-dihydroxyphenylalanine, cystine, 4hydroxyproline), $\mathrm{N}$-acetylated amino acids (e.g. N-acetyl-tyrosine, $\mathrm{N}$-acetyl-lysine), amines (e.g. ethanolamine, butanediamine), pyrimidines and purines (thymin, uracil, ureate), sugars (e.g. glucose), acylglycines (hippurate, propionylglycine, hexanoylglycine), and others (e.g. succinylacetone, indoleacetate, urea, cholesterol, furan-2,5-dicarboxylate).

\subsubsection{Analysis of urine acidic extract in relation to organic acidurias}

A large subgroup of Inherited Metabolic Disorders called organic acidurias is characteristic by increased levels of organic acids in urine or the presence of pathological ones not appearing in healthy urine. The diagnosis of organic acidurias is commonly performed by the analysis of urine after acidic extraction. Besides organic acids, some other types of metabolites also serving as pathological markers, are extracted.

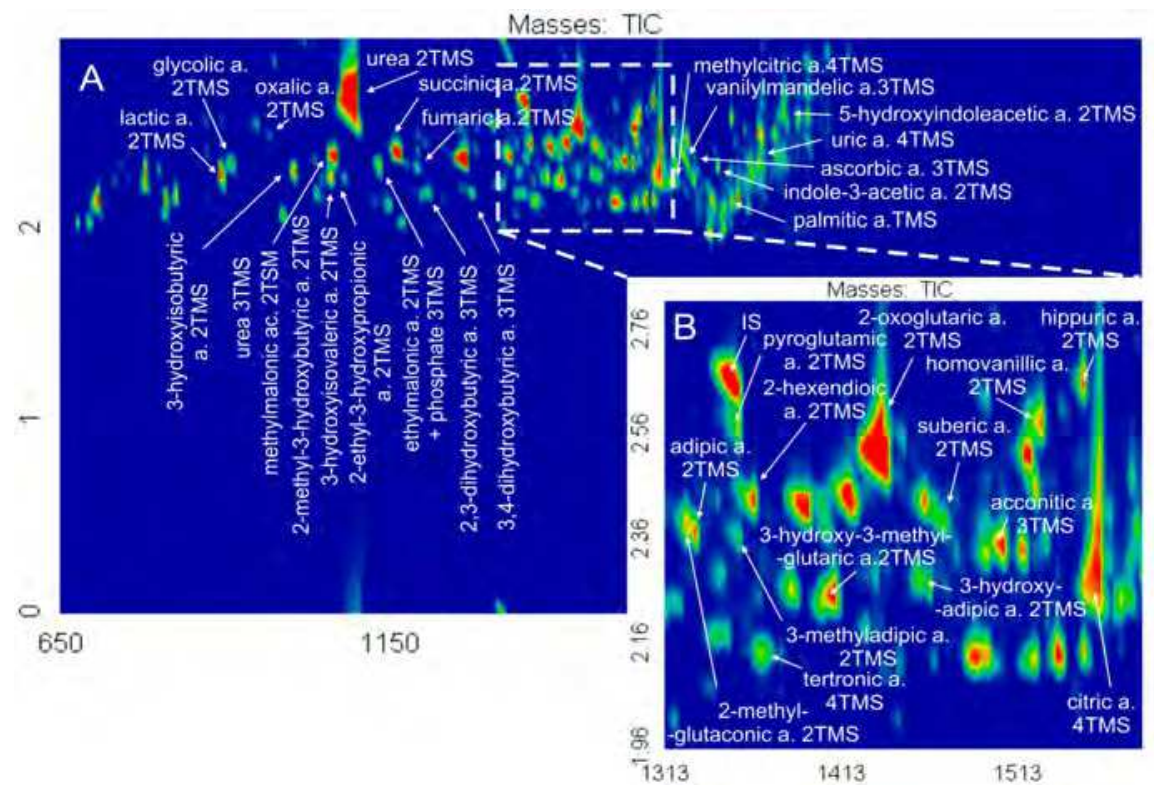

Fig. 5. GC $\times$ GC-TOF-MS contour plot from the analysis of healthy urine (A) and enlarged part (B) 
Automated data processing with peak finding above S/N 200 was applied to the data, which resulted in the detection of 1353-3420 peaks in the set of studied urines. After sorting out GC column bleed peaks and the peaks belonging to the derivatization reagent, some $60 \%$ of the peaks remained. They are naturally occurring metabolites, pathological metabolites, nutrition artifacts, and drug artifacts, but most of the compounds are still not clearly identified. Our TMS Reference contains 153 identified and confirmed urine chemical species (from all 268 in the TMS Reference). In the Figure 5 is shown a 2D contour plot of healthy urine.

To evaluate the newly developed GC $\times$ GC method as well as the data processing strategy described above, we selected external quality control samples (ERNDIM, http://www.erndim.unibas.ch/) and one sample from an asymptomatic patient with medium-chain acyl-CoA dehydrogenase deficiency, who had been diagnosed by neonatal screening sixth days after birth. Since the patient was in a non-crisis state, many biochemical markers of the disease were in normal levels, so he could be missed by GC-MS. Using GC $\times$ GC-TOF-MS with the TMS Reference we found both hexanoylglycine peaks, which, although present at low concentrations, are obviously pathological markers and confirm the presence of the disease. Figure 6 illustrates the major benefit of our approach - separation of main markers of the disease from an excess of naturally occurred metabolite. For more details see (Wojtowicz et al., 2010).
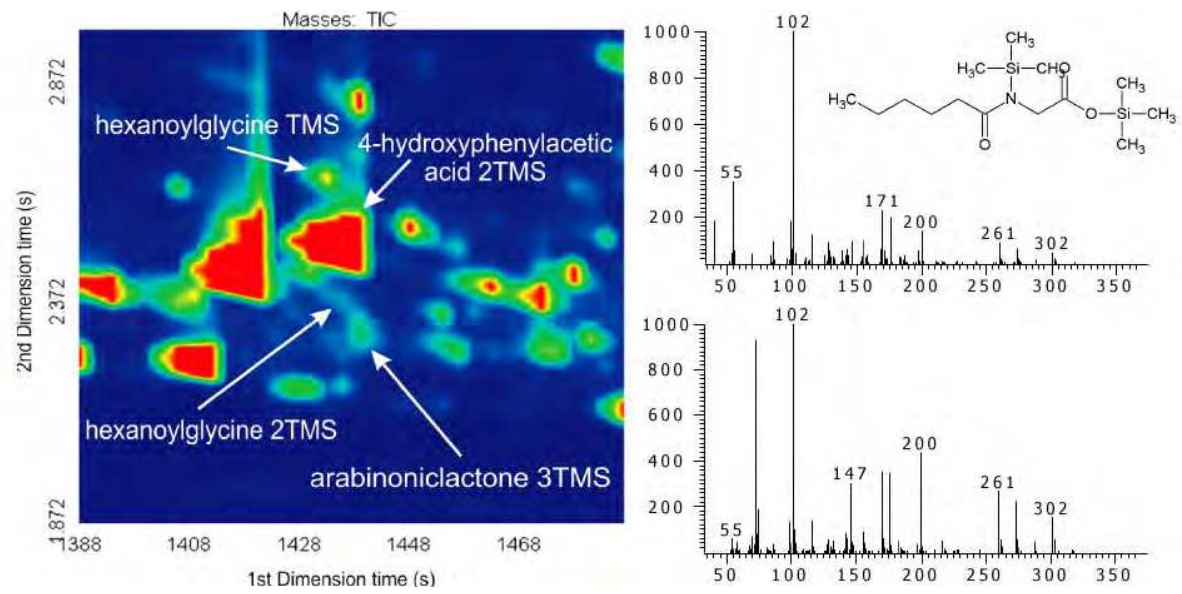

Fig. 6. Enlarged part of a contour plot from the analysis of urine from a patient with medium-chain acyl-CoA dehydrogenase deficiency. Two peaks of hexanoylglycine derivatives (1 and 2TMS) are resolved from a large peak of 4-hydroxyphenylacetic acid 2TMS. The deconvoluted spectrum (up) and the library hit belonging to the 2TMS derivate are shown (similarity 798)

\subsubsection{Analysis of cultured human skin fibroblasts - comparison of trypsin treatment vs. quenching}

The influence of most of external factors on the cell metabolomes is minimized in a culture where a defined extracellular environment takes place. To collect reliable metabolome data sets, culture and sampling conditions are crucial. The accurate analysis of intracellular metabolites requires a reliable sampling technique. Metabolites are generally labile species 
and their reactions occur on a time scale much shorter than that of large molecule synthesis or degradation, with substantial changes in small molecule concentrations possible during a time scale of seconds (Canelas et al., 2008).

The metabolomic analysis of adherent cell cultures presents a complex challenge, mostly given by limited sample sizes. The rapid quenching of the intracellular metabolism, simultaneously with the considerable removal of superabundant growing medium, are the main prerequisites. As a result of a known rapid turnover of intracellular metabolites, the sampling process should be very fast and cause minimal metabolome loss as a result of cell leakage. In this study, we compared trypsinization as the classical procedure for adherent cell harvesting (Dettmer et al., 2011) with the simple quenching procedure developed in our laboratory.

A set of studied fibroblasts has been analyzed by a GC $\times$ GC-TOF-MS method and the data was subjected to automated data processing with peak finding above S/N 200, which resulted in the detection of 431-601 peaks. Similarly as described in the section 5.1, our TMS Reference contains 72 identified and confirmed intracellular chemical species, from all 268 in the TMS Reference (Table 1). In the Figure 7 a 2D contour plot of analysis of the intracellular metabolites extracted from spray-quenched human cultured skin fibroblasts is shown.

\begin{tabular}{llll}
\hline Acetate & 2,3-Dihydroxybutyrate & 4-Hydroxyproline & 2-Oxovalerate \\
Aconitate & 3,4-Dihydroxybutyrate & Cholesterol & Palmitate \\
Adipate & Glucose & Isoleucine & Panthotenate \\
Alanine & Glutamine & Itaconate & Phenylalanine \\
2-Aminoadipate & Glutarate & Lactate & Phosphate \\
2-Aminobutyrate & Glycerol & Laurate & Picolinate \\
4-Aminobutyrate & Glycerate & Leucine & Proline \\
Aspargine & Glycine & Lysine & Pyruvate \\
Aspartate & Fumarate & Malate & Serine \\
Azelaic acid & Hexenedioate & Maleate & Succinate \\
$\beta$-Alanine & Hippurate & Mesaconate & Stearate \\
Benzoate & Histidine & Methionine & Threonate \\
Capric acid & 2-Hydroxyisobutyrate & Myo-inositol & Threonine \\
Citraconate & 3-Hydroxyisobutyrate & Oleate & Tryptophan \\
Citrate & 2-Hydroxybutyrate & Ornithine & Tyrosine \\
Cystathionine & 2-Hydroxyisobutyrate & 2-Oxoglutarate & Uracil \\
Cysteine & 2-Hydroxyglutarate & 2-Oxo-3-methylvalerate & Urea \\
Diphosphate & 3-Hydroxyhippurate & 5-Oxoproline & Valine \\
\hline
\end{tabular}

Table 1. The list of 72 unique metabolites identified and confirmed in extracts of human cultured skin fibroblasts by GC × GC-TOF-MS

In order to evaluate the effect of quenching vs. trypsinization, a cellular metabolome was determined in fibroblast cultures ( $\mathrm{n}=6$ for each method) from a single cell line. Data from analyses were corrected to percentages of a sum. The obtained compositional data were statistically analyzed. The geometric means for the single compounds were calculated. In order to be able to deal with Gaussian distribution of single compounds for variance analysis the data were transformed by the following equation $\left[1 / \operatorname{sqrt}(2)^{*} \log (x /(1-x))\right]$, that represents a special case of so-called isometric log-ratio transformation (Egozcue et al., 2003). The results from trypsin and quenching approaches were compared as the natural 
logarithms of ratios of means and variations (Figure 8) and multivariate statistics - PCA and CA (Figure 9). It is clearly visible that the quenching technique substantially affects the concentrations of a number of metabolites. Several metabolites (e.g. citrate, lysine) differ by an order of magnitude. From the variations it is also evident that sample preparation by means of conventional trypsinization provides substantially more variable data in comparison to quenching by means of spraying.

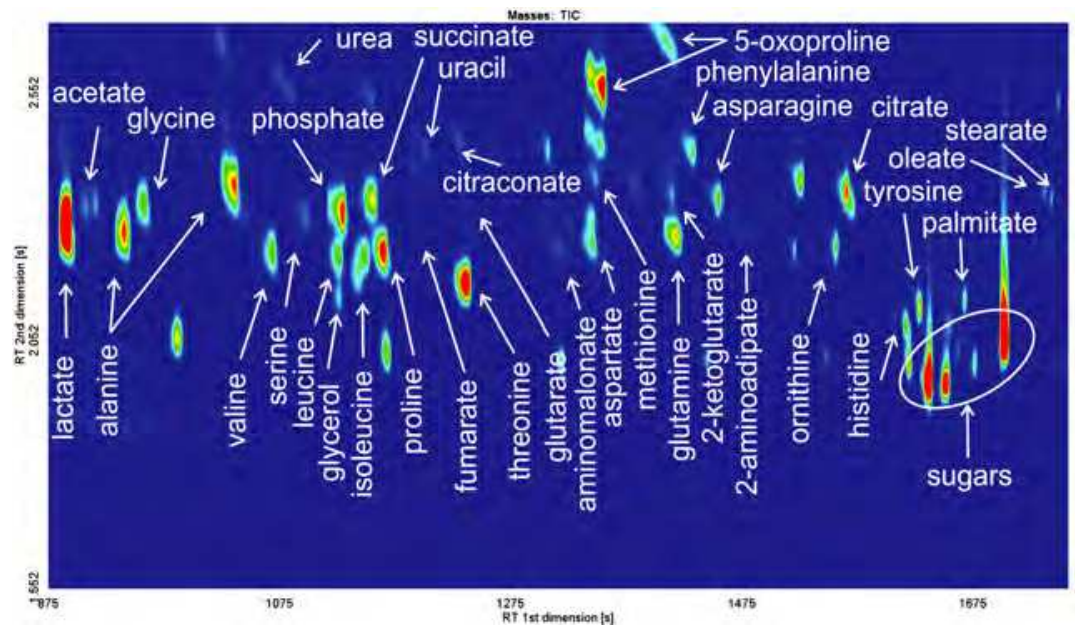

Fig. 7. GC $\times$ GC contour plot of analysis of the intracellular metabolites extracted from spray-quenched human cultured skin fibroblasts

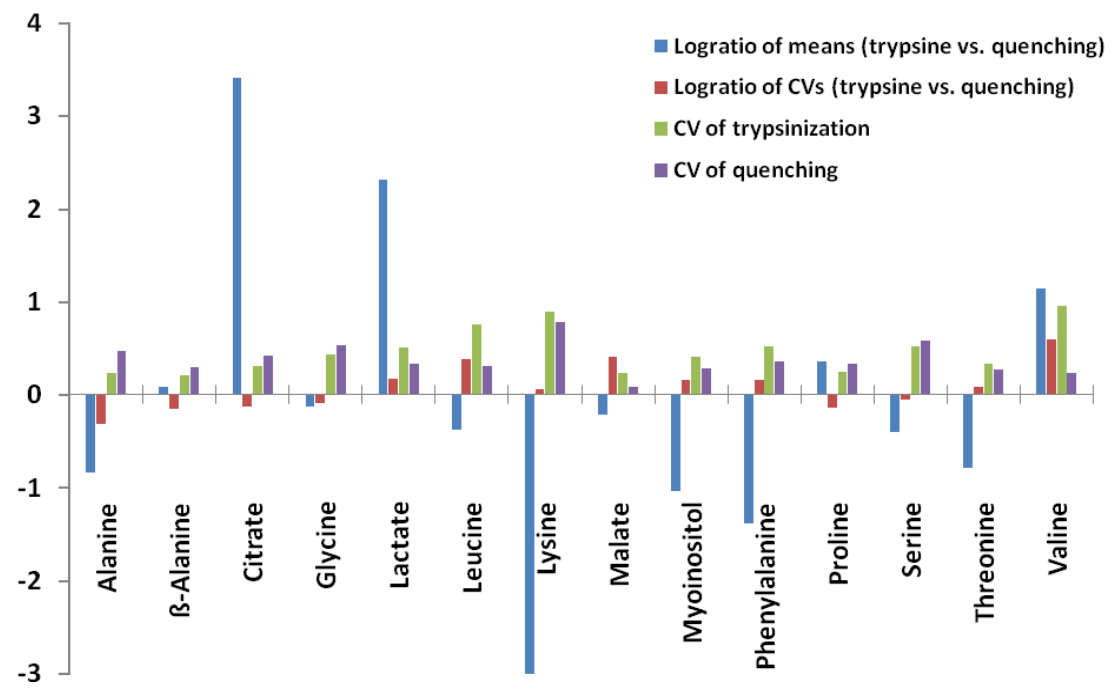

Fig. 8. The comparison of the intracellular levels of mostly deviating metabolites in trypsin treated and quenched cells. Natural logarithms of ratios of means and coefficients of variation $(\mathrm{CV})$ are shown 

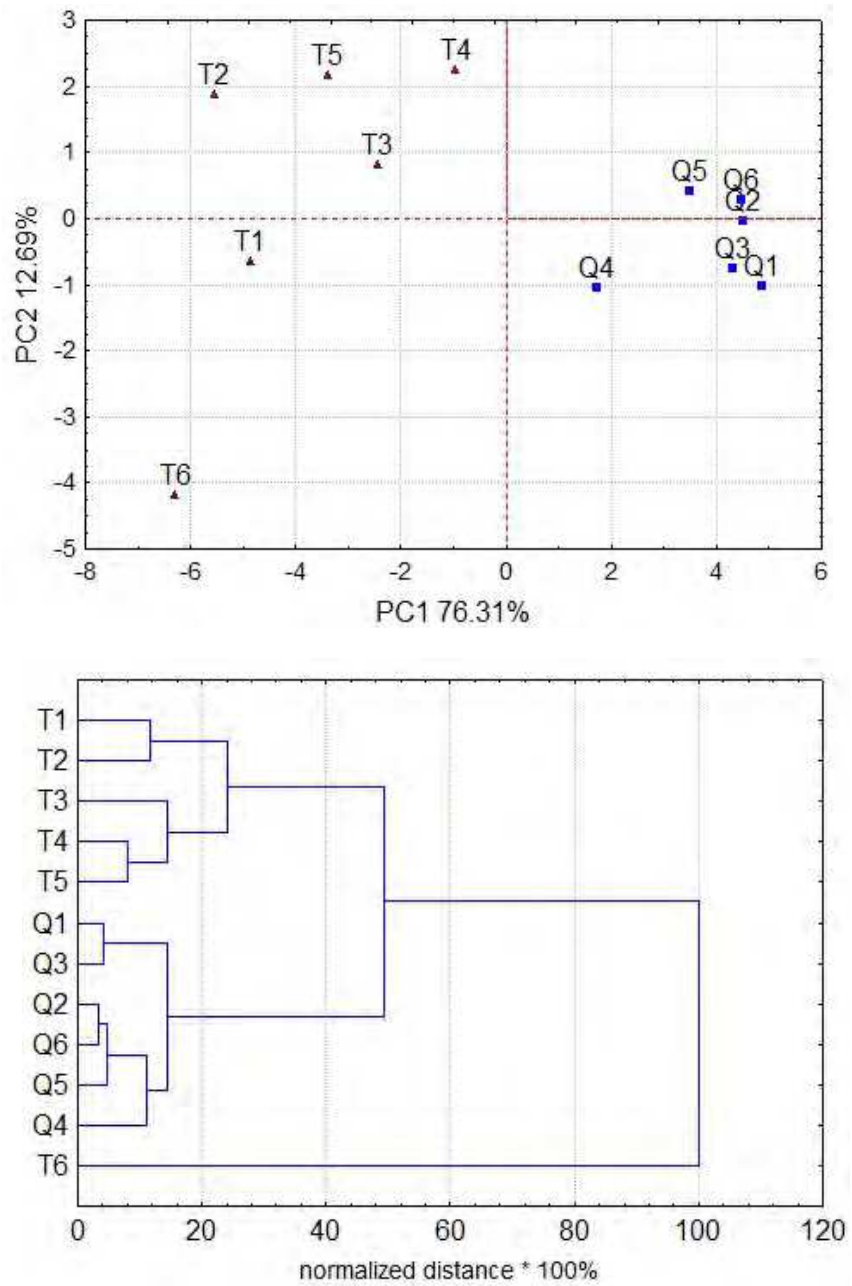

Fig. 9. PCA projection of the cases and CA dendrogram (complete-linkage, Euclidian distance) for the comparison of two cell harvesting methods (based on the listed 72 metabolites). T1-T6 trypsinization, Q1-Q6 quenching

\subsection{MCF approach}

EZfaast standard solution (contains 32 amino acids and dipeptides), 20 intracellular extracts from quenched fibroblasts, and 20 plasma samples derivatized by MCF were analyzed by a GC $\times$ GC-TOF-MS method and subjected to data processing procedure similarly as described in previous sections and the MCF Reference has been made.

Our MCF Reference currently contains 185 analytes - they are mostly organic acids and their derivates (the same as in the TMS approach) and compounds containing amino group (the exception is arginine because of the thermal instability of its MCF derivative that carries 
a free guanidine group). Sugars are another group of compounds that cannot be detected by this approach. But that can be an advantage while e.g. cell extracts usually contains an excess of sugars that can make the obtained chromatograms not easily interpretable and some important markers can be masked. Table 2 shows some MCF-Reference based data (2D retention characteristics, unique masses - the characteristic mass identified by the ChromaTOF software, and three main ions from the MS spectra).

\begin{tabular}{lccccccc}
\hline Amino acid & $\begin{array}{c}\text { 1D; } 2 \mathrm{D} \\
\mathrm{RT}[\mathrm{s}]\end{array}$ & $\mathrm{RI}$ & $\begin{array}{c}\text { Unique } \\
\text { mass }\end{array}$ & $\begin{array}{c}\text { Derivate } \\
\mathrm{Mr}\end{array}$ & $\begin{array}{c}\text { Base } \\
\text { peak }\end{array}$ & P2/\% & P3/\% \\
\hline Alanine & $476 ; 2.44$ & 1142 & 102 & 161 & 102 & $42 / 65$ & $59 / 63$ \\
Glycine & $484 ; 2.50$ & 1152 & 71 & 147 & 88 & $44 / 62$ & $56 / 55$ \\
Sarkosine & $504 ; 2.39$ & 1179 & 102 & 161 & 102 & $42 / 78$ & $59 / 49$ \\
Valine & $556 ; 2.38$ & 1255 & 130 & 189 & 130 & $42 / 88$ & $59 / 82$ \\
2-Aminobutyric & $564 ; 2.40$ & 1268 & 88 & 175 & 88 & $44 / 51$ & $56 / 41$ \\
acid & $600,2.38$ & 1327 & 88 & 203 & 88 & $59 / 46$ & $43 / 43$ \\
Leucine & $612 ; 2.58$ & 1348 & 115 & 191 & 115 & $59 / 56$ & $42 / 37$ \\
Threonine & $632 ; 2.64$ & 1383 & 128 & 187 & 41 & $128 / 82$ & $41 / 37$ \\
Proline & $636 ; 2.64$ & 1390 & 127 & 204 & 42 & $127 / 75$ & $56 / 72$ \\
Asparagine & $668 ; 2.56$ & 1450 & 160 & 219 & 42 & $59 / 88$ & $160 / 69$ \\
Aspargic acid & $732 ; 2.54$ & 1578 & 114 & 233 & 114 & $59 / 76$ & $42 / 70$ \\
Glutamic acid & $740 ; 2.64$ & 1596 & 61 & 221 & 61 & $59 / 48$ & $115 / 40$ \\
Methionine & $744 ; 2.71$ & 1604 & 144 & 203 & 144 & $41 / 56$ & $59 / 47$ \\
4-Hydroxyproline & $784 ; 2.51$ & 1693 & 114 & 247 & 114 & $55 / 70$ & $59 / 69$ \\
2-Aminoadipic acid & $784 ; 2.69$ & 1694 & 59 & 193 & 59 & $42 / 77$ & $44 / 59$ \\
Cysteine & $796 ; 2.68$ & 1720 & 42 & 237 & 42 & $91 / 65$ & $59 / 57$ \\
Phenylalanine & $840 ; 3.00$ & 1872 & 84 & 218 & 84 & $44 / 42$ & $59 / 41$ \\
Glutamine & $884 ; 2.71$ & 1937 & 128 & 262 & 128 & $42 / 51$ & $59 / 51$ \\
Ornithine & $920 ; 2.76$ & 2033 & 142 & 218 & 142 & $59 / 82$ & $44 / 55$ \\
Lysine & $940 ; 3.00$ & 2088 & 59 & 227 & 59 & $81 / 76$ & $42 / 73$ \\
Histidine & $980 ; 3.00$ & 2203 & 121 & 252 & 121 & $59 / 90$ & $42 / 73$ \\
Tyrosine & $1052 ; 3.78$ & 2424 & 130 & 276 & 130 & $77 / 18$ & $51 / 11$ \\
Tryptophan & & & & & & & \\
\hline
\end{tabular}

Table 2. Table of 22 selected amino acids derivatized via MCF presented in our Reference. 1D and 2D RT - retention time in first and second dimension, RI - retention index (calculated on the basis of absolute RT), P2 and P3/\% - second and third most abundant peak/percentage of its intensity to the base peak

\subsubsection{Analysis of cultured human skin fibroblasts - effect of cultivation with 5-FU}

Since its synthesis, 5-FU has become one of the most widely used anticancer drugs for a variety of common malignancies, including cancers of the colon, breast, skin, and head and neck. 5-FU has been used as a component of both first-line chemotherapy regimens and in salvage regimens. Despite extensive clinical experience with 5-FU and its effective antitumor activity, many concerns remain about the optimal use of this agent.

5-FU is a prodrug, which is subject to both anabolism and catabolism. The cytotoxic activity of 5-FU depends on its anabolism to nucleotides, which exert their effects through inhibition 
of thymidylate synthase activity or incorporation into RNA and/or DNA. The catabolism of 5 -FU has been better understood only in recent years. The products of 5-FU catabolism have been linked to several 5-FU toxicities, including neurotoxicity (Grem, 2000; Kuhn, 2001).

This study was to show the differences in the fibroblasts metabolome after cultivation with addition of 5-FU against the non-treated controls ( $\mathrm{n}=3$ for each 6,24 , and $48 \mathrm{~h}$ treatment, and without treatment, respectively), all from a single cell line. Data processing with peak
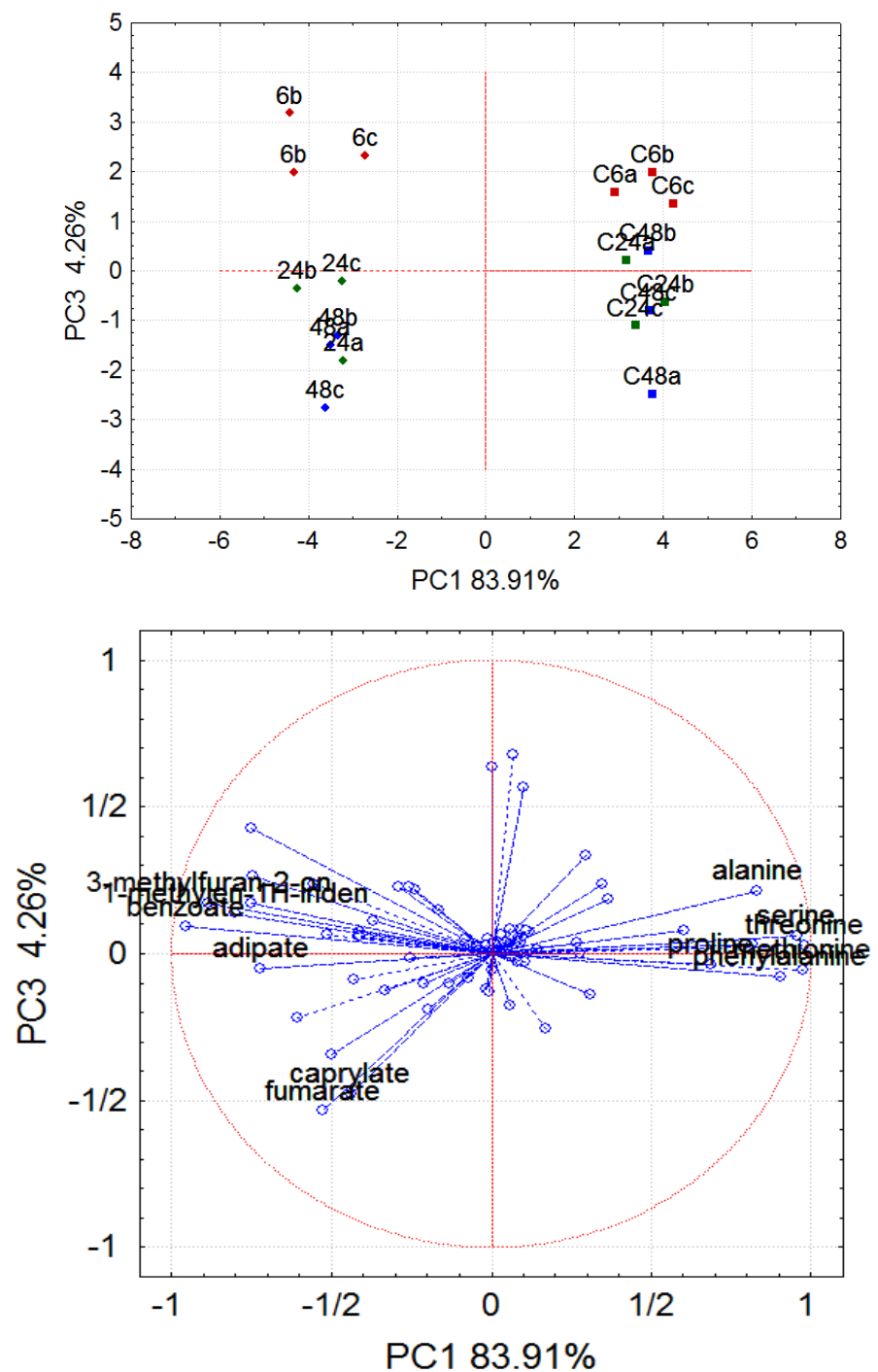

Fig. 10. PCA projection of the cases (up) and the loading plot (down) for the comparison of the effect of 5-FU on the fibroblast cultivation. Triplicates $(a, b, c)$ for 6,24 or 48 hours of cultivation with presence of 5-FU and controls (C) are shown 
finding above S/N 200 was applied to the data, which resulted in the detection of 393-451 peaks in the set of studied fibroblasts. Our MCF Reference contains 78 identified and confirmed intracellular chemical species (from all 185 in the MCF Reference). Data from analyses were corrected to percentages of a sum, normalized to the unit standard deviation, and statistically analyzed through PCA (Figure 10). Figure 11 shows the differences for the most deviating metabolites. From the presented graphs it is clearly visible that cultivation with 5-FU influenced fibroblasts' metabolism.

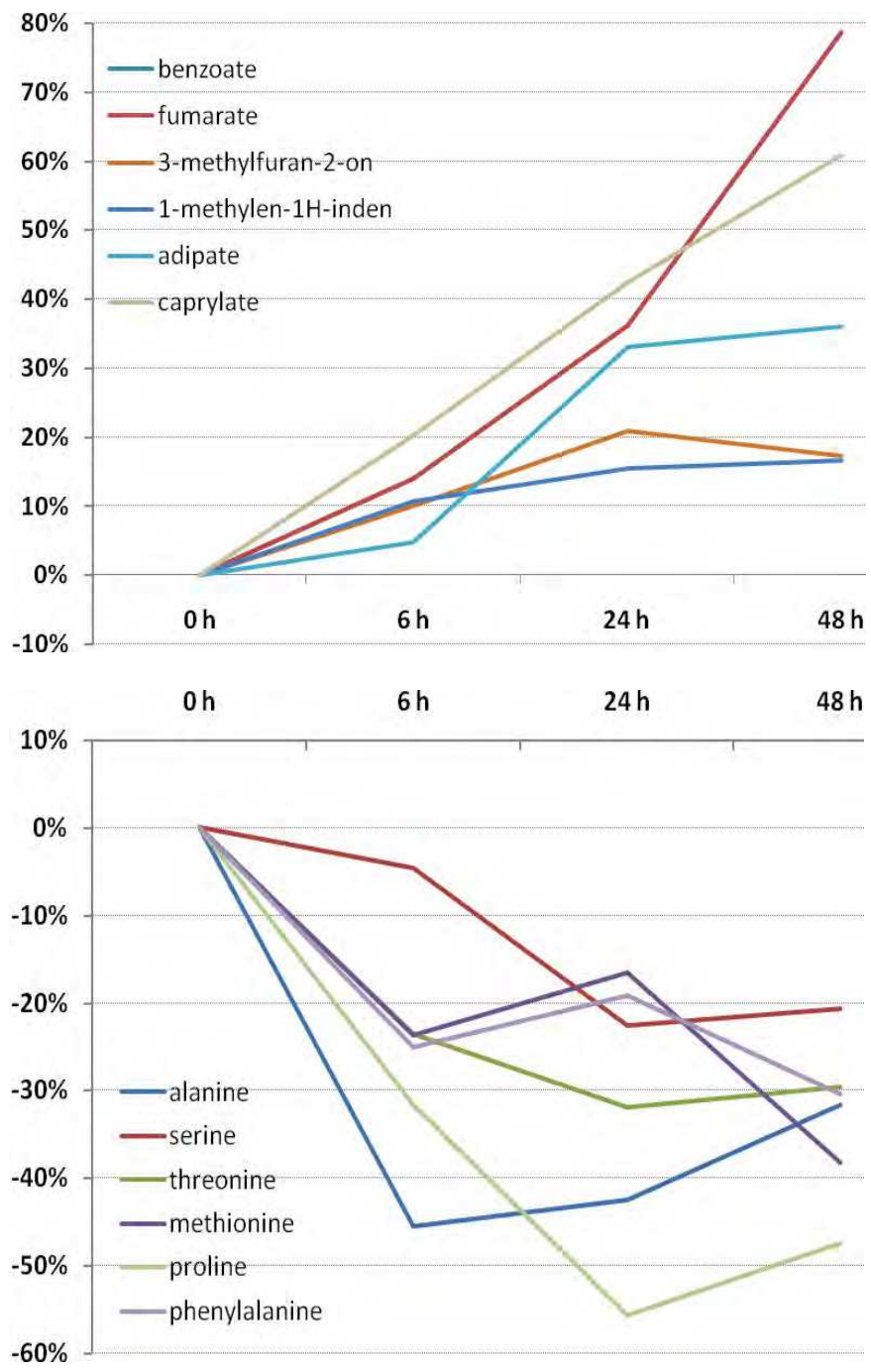

Fig. 11. Graph of the most increasing (up) and decreasing (down) intracellular metabolites influenced by 5-FU. Differences are quantified as percentages of influenced response to the non-influenced ones. 


\subsubsection{Analysis of human plasma in relation to metabolic disorders}

In this work we focused on the diagnosis of Inherited Metabolic Disorders in plasma samples using a targeted metabolomic approach by GC × GC-TOF-MS.
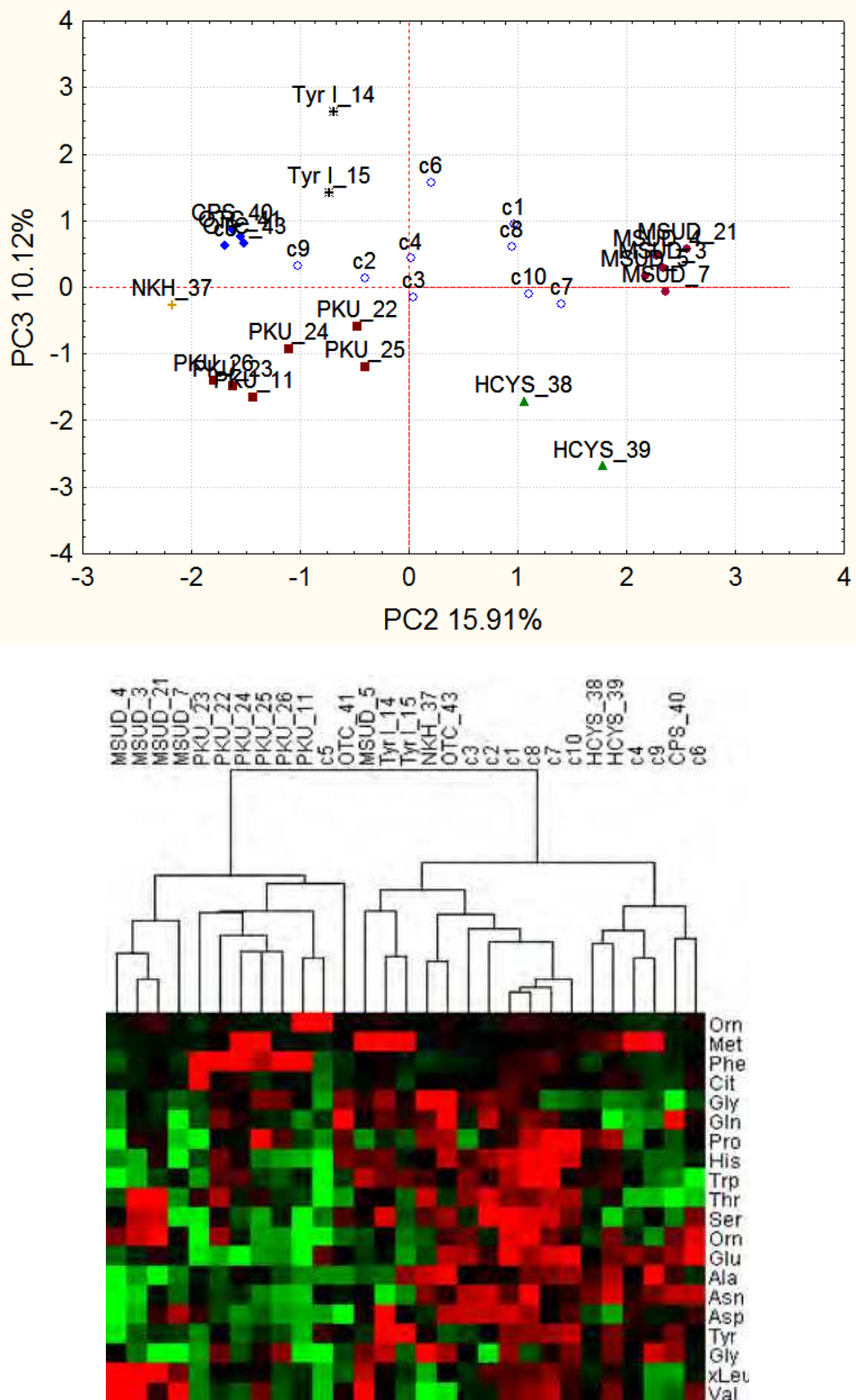

Fig. 12. PCA projection of the cases (up) and a heat map (down) visualized for selected amino acids from the analysis of human plasma 
Automated data processing with peak finding above S/N 50 was applied to the data, which resulted in the detection of 408-594 peaks in the set of studied plasma samples. Our MCF Reference contains 65 identified and confirmed plasma chemical species (from all 185 in the MCF Reference).

Prior to statistical analysis the centred logratio (clr) transformation was applied. Data were evaluated using PCA and CA based on hierarchical clustering with a complete-linkage Euclidian distance method (visualized as a heat map) - Figure 12.

All the patients' samples were discriminated from the controls by appropriate metabolites in the PCA analysis. Patients with identical disease were recognized using the PCA approach and also clustered together.

\section{Conclusion}

This technique has been shown to be very powerful for the purpose of comprehensive sample profiling. On selected samples we demonstrated that higher separation power of GC $\times$ GC can help in removing co-elutions occurring in one dimensional approach. GC $\times$ GC is a valuable tool in metabolomic analysis of many biological matrices and enables diagnosing metabolic disorders. The great benefit is data processing that can be fully automated, what strongly simplify operator's effort and increases the sample throughput.

\section{Acknowledgement}

Infrastructural part of this project (Institute of Molecular and Translational Medicine) was supported from the Operational programme Research and Development for Innovations (project CZ.1.05/2.1.00/01.0030).

\section{References}

Adahchour, M., Beens, J. \& Brinkman, U. A. T. (2008). Recent developments in the application of comprehensive two-dimensional gas chromatography. Journal of Chromatography A, Vol. 1186, No. 1-2, pp. 67-108, ISSN 0021-9673

Adahchour, M., Beens, J., Vreuls, R. J. J. \& Brinkman, U. A. T. (2006). Recent developments in comprehensive two-dimensional gas chromatography (GC $\times$ GC). TrAC Trends in Analytical Chemistry, Vol. 25, No. 6, pp. 540-553, ISSN 01659936

Beens, J. \& Brinkman, U. A. T. (2005). Comprehensive two-dimensional gas chromatography - a powerful and versatile technique. The Analyst, Vol. 130, No. 2, pp. 123-127, ISSN 1364-5528

Blumberg, L. M., David, F., Klee, M. S. \& Sandra, P. (2008). Comparison of one-dimensional and comprehensive two-dimensional separations by gas chromatography. Journal of Chromatography A, Vol. 1188, No. 1, pp. 2-16, ISSN 0021-9673

Boernsen, K. O., Gatzek, S. \& Imbert, G. (2005). Controlled protein precipitation in combination with chip-based nanospray infusion mass spectrometry. An approach for metabolomics profiling of plasma. Analytical Chemistry, Vol. 77, No. 22, pp. 7255-7264, ISSN 0003-2700 
Canelas, A. B., Ras, C., ten Pierick, A., van Dam, J. C., Heijnen, J. J. \& Van Gulik, W. M. (2008). Leakage-free rapid quenching technique for yeast metabolomics. Metabolomics, Vol. 4, No. 3, pp. 226-239, ISSN 1573-3882

Dettmer, K., Nurnberger, N., Kaspar, H., Gruber, M. A., Almstetter, M. F. \& Oefner, P. J. (2011). Metabolite extraction from adherently growing mammalian cells for metabolomics studies: optimization of harvesting and extraction protocols. Analytical and Bioanalytical Chemistry, Vol. 399, No. 3, pp. 1127-1139, ISSN 1618-2650

Edwards, M., Mostafa, A. \& Gorecki, T. (2011). Modulation in comprehensive twodimensional gas chromatography: 20 years of innovation. Analytical and Bioanalytical Chemistry, DOI 10.1007/ s00216-011-5100-6, ISSN 1618-2650

Egozcue, J.J., Pawlowsky-Glahn, V., Mateu-Figueras G. \& Barceló-Vidal, C. (2003). Isometric logratio transformations for compositional data analysis. Mathematical Geology, Vol. 35, No. 3, pp. 279-300, ISSN 0882-8121

Gorecki, T., Harynuk, J. \& Panic, O. (2004). The evolution of comprehensive twodimensional gas chromatography (GC x GC). Journal of Separation Science, Vol. 27, No. 5-6, pp. 359-379, ISSN 1615-9306

Grem, J. L. (2000). 5-Fluorouracil: forty-plus and still ticking. A review of its preclinical and clinical development. Investigation New Drugs, Vol. 18, No. 4, pp. 299-313, ISSN 0167-6997

Griffiths, J. R. \& Chung, Y. L. (2008). Using metabolomics to monitor anticancer drugs. Oncogenes Meet Metabolism: From Deregulated Genes to a Broader Understanding of Tumour Physiology, Vol. 4, pp. 55-78, ISSN 0947-6075

Husek, P. \& Simek, P. (2006). Alkyl chloroformates in sample derivatization strategies for GC analysis. Review on a decade use of the reagents as esterifying agents. Current Pharmaceutical Analysis, Vol. 2, No. 1, pp. 23-43, ISSN 1573-4129

Janeckova, H., Hron, K., Wojtowicz, P., Hlidkova, E., Baresova, A., Friedecky, D., Zidkova, L., Hornik, P., Behulova, D., Prochazkova, D., Vinohradska, H., Peskova, K., Bruheim, P., Smolka, V., Stastna, S. \& Adam, T. (2011). Targeted metabolomic analysis of plasma samples for the diagnosis of inherited metabolic disorders. Journal of Chromatography A, DOI 10.1016/j.chroma.2011.09.074, ISSN 1873-3778

Kim, S., Fang, A. Q., Wang, B., Jeong, J. \& Zhang, X. (2011). An optimal peak alignment for comprehensive two-dimensional gas chromatography mass spectrometry using mixture similarity measure. Bioinformatics, Vol. 27, No. 12, pp. 1660-1666, ISSN 1367-4803

Koek, M. M., Muilwijk, B., van der Werf, M. J. \& Hankemeier, T. (2006). Microbial metabolomics with gas chromatography/mass spectrometry. Analytical Chemistry, Vol. 78, No. 4, pp. 1272-1281, ISSN 0003-2700

Koek, M. M., Muilwijk, B., van Stee, L. L. \& Hankemeier, T. (2008). Higher mass loadability in comprehensive two-dimensional gas chromatography-mass spectrometry for improved analytical performance in metabolomics analysis. Journal of Chromatography A, Vol. 1186, No. 1-2, pp. 420-429, ISSN 0021-9673

Koek, M. M., van der Kloet, F. M., Kleemann, R., Kooistra, T., Verheij, E. R. \& Hankemeier, T. (2011). Semi-automated non-target processing in GC x GC-MS metabolomics analysis: applicability for biomedical studies. Metabolomics, Vol. 7, No. 1, pp. 1-14, ISSN 1573-3890 
Kouremenos, K. A., Pitt, J. \& Marriott, P. J. (2010). Metabolic profiling of infant urine using comprehensive two-dimensional gas chromatography: Application to the diagnosis of organic acidurias and biomarker discovery. Journal of Chromatography A, Vol. 1217, No. 1, pp. 104-111, ISSN 1873-3778

Kuhn, J. G. (2001). Fluorouracil and the new oral fluorinated pyrimidines. The Annals of Pharmacotherapy, Vol. 35, No. 2, pp. 217-227, ISSN 1060-0280

Li, X., Xu, Z., Lu, X., Yang, X., Yin, P., Kong, H., Yu, Y. \& Xu, G. (2009). Comprehensive twodimensional gas chromatography/time-of-flight mass spectrometry for metabonomics: Biomarker discovery for diabetes mellitus. Analytica Chimica Acta, Vol. 633, No. 2, pp. 257-262, ISSN 1873-4324

Liu, Z. \& Phillips, J. B. (1991). Comprehensive Two-Dimensional Gas Chromatography using an On-Column Thermal Modulator Interface. Journal of Chromatographic Science, Vol. 29, No. 6, pp. 227-231, ISSN 0021-9665

Little, J. L. (1999). Artifacts in trimethylsilyl derivatization reactions and ways to avoid them. Journal of Chromatography A, Vol. 844, No.1-2, pp. 1-22. ISSN 0021-9673

Mitrevski, B. S., Brenna, J. T., Zhang, Y. \& Marriott, P. J. (2008). Application of comprehensive two-dimensional gas chromatography to sterols analysis. Joutnal of Chromatography A, Vol. 1214, No. 1-2, pp. 134-142, ISSN 0021-9673

Mitrevski, B. S., Wilairat, P. \& Marriott, P. J. (2010). Comprehensive two-dimensional gas chromatography improves separation and identification of anabolic agents in doping control. Journal of Chromatography A, Vol. 1217, No. 1, pp. 127-135, ISSN 1873-3778

Ong, C. N., Xu, F. G. \& Zou, L. (2010). Experiment-originated variations, and multi-peak and multi-origination phenomena in derivatization-based GC-MS metabolomics. Trends in Analytical Chemistry, Vol. 29, No. 3, pp. 269-280, ISSN 0165-9936

Oresic, M., Tang, J., Seppanen-Laakso, T., Mattila, I., Saarni, S. E., Saarni, S. I., Lonnqvist, J., Sysi-Aho, M., Hyotylainen, T., Perala, J. \& Suvisaari, J. (2011). Metabolome in schizophrenia and other psychotic disorders: a general population-based study. Genome Medicine, Vol. 3, No. 3, pp. 19-32, ISSN 1756-994X

Panic, O., Gorecki, T., McNeish, C., Goldstein, A. H., Williams, B. J., Worton, D. R., Hering, S. V. \& Kreisberg, N. M. (2011). Development of a new consumable-free thermal modulator for comprehensive two-dimensional gas chromatography. Journal of Chromatography A, Vol. 1218, No. 20, pp. 3070-3079, ISSN 1873-3778

Pasikanti, K. K., Norasmara, J., Cai, S. R., Mahendran, R., Esuvaranathan, K., Ho, P. C. \& Chan, E. C. Y (2010). Metabolic footprinting of tumorigenic and nontumorigenic uroepithelial cells using two-dimensional gas chromatography time-of-flight mass spectrometry. Analytical and Bioanalytical Chemistry, Vol. 398, No. 3, pp. 1285-1293, ISSN 1618-2642

Rabinowitz, J. D., Munger, J., Bajad, S. U., Coller, H. A. \& Shenk, T. (2006). Dynamics of the cellular metabolome during human cytomegalovirus infection. PLoS Pathogens, Vol. 2, No. 12, pp. 1165-1175, ISSN 1553-7366

Reichenbach, S. E., Ni, M. T., Kottapalli, V. \& Visvanathan, A. (2004). Information technologies for comprehensive two-dimensional gas chromatography. Chemometrics and Intelligent Laboratory Systems, Vol. 71, No. 2, pp. 107-120, ISSN 0169-7439 
Ryan, D., Morrison, P. \& Marriott, P. (2005). Orthogonality considerations in comprehensive two-dimensional gas chromatography. Journal of Chromatography A, Vol. 1071, No. 1-2, pp. 47-53, ISSN 0021-9673

Sarker, D. \& Workman, P. (2007). Pharmacodynamic biomarkers for molecular cancer therapeutics. Advances in Cancer Research, Vol. 96, pp. 213-268, ISSN 0065-230X

Wadhier, M. C., Almstetter, M. F., Nurnberger, N., Gruber, M. A., Dettmer, K. \& Oefner, P. J. (2011). Improved enantiomer resolution and quantification of free D-amino acids in serum and urine by comprehensive two-dimensional gas chromatography-time-offlight mass spectrometry. Journal of Chromatography A, Vol. 1218, No. 28, pp. 45374544, ISSN 0021-9673

Walsh, M. C., Brennan, L., Malthouse, J. P. G., Roche, H. M. \& Gibney, M. J. (2006). Effect of acute dietary standardization on the urinary, plasma, and salivary metabolomic profiles of healthy humans. American Journal of Clinical Nutrition, Vol. 84, No. 3, pp. 531-539, ISSN 0002-9165

Wang, B., Fang, A. Q., Heim, J., Bogdanov, B., Pugh, S., Libardoni, M. \& Zhang, X. A. (2010). DISCO: Distance and Spectrum Correlation Optimization Alignment for TwoDimensional Gas Chromatography Time-of-Flight Mass Spectrometry-Based Metabolomics. Analytical Chemistry, Vol. 82, No. 12, pp. 5069-5081, ISSN 0003-2700

Weiss, R. H., Kind, T., Tolstikov, V. \& Fiehn, O. (2007). A comprehensive urinary metabolomic approach for identifying kidney cancer. Analytical Biochemistry, Vol. 363, No. 2, pp. 185-195, ISSN 0003-2697

Wells, R. J. (1999). Recent advances in non-silylation derivatization techniques for gas chromatography. Journal of Chromatography A, Vol. 843, No. 1-2, 1-18. ISSN 00219673

Wojtowicz, P., Zrostlikova, J., Kovalczuk, T., Schurek, J. \& Adam, T. (2010). Evaluation of comprehensive two-dimensional gas chromatography coupled to time-of-flight mass spectrometry for the diagnosis of inherited metabolic disorders using an automated data processing strategy. Journal of Chromatography A, Vol. 51, No. 1217, pp. 8054-8061, ISSN 1873-3778

Workman, P., Aboagye, E. O., Chung, Y. L., Griffiths, J. R., Hart, R., Leach, M. O., Maxwell, R. J., McSheehy, P. M. J., Price, P. M. \& Zweit, J. (2006). Minimally invasive pharmacokinetic and pharmacodynamic technologies in hypothesis-testing clinical trials of innovative therapies. Journal of the National Cancer Institute, Vol. 98, No. 9, pp. 580-598, ISSN 0027-8874

Zapadlo, M., Krupcik, J., Kovalczuk, T., Majek, P., Spanik, I., Armstrong, D. W. \& Sandra, P. (2011). Enhanced comprehensive two-dimensional gas chromatographic resolution of polychlorinated biphenyls on a non-polar polysiloxane and an ionic liquid column series. Journal of Chromatography A, Vol. 1218, No. 5, pp. 746-751, ISSN 00219673

Zhu, S. K. (2009). Effect of column combinations on two-dimensional separation in comprehensive two-dimensional gas chromatography: Estimation of orthogonality and exploring of mechanism. Journal of Chromatography A, Vol. 1216, No. 15, pp. 3312-3317, ISSN 0021-9673 


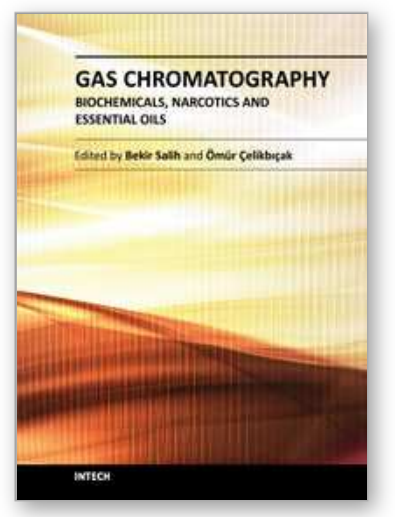

\author{
Gas Chromatography - Biochemicals, Narcotics and Essential Oils \\ Edited by Dr. Bekir Salih
}

ISBN 978-953-51-0295-3

Hard cover, 236 pages

Publisher InTech

Published online 09, March, 2012

Published in print edition March, 2012

Gas Chromatography involves the study of various vaporizable molecules in chemistry and the other related research fields. This analytical method has a number of features and advantages that make it an extremely valuable tool for the identification, quantification and structural elucidation of organic molecules. This book provides detailed gas chromatography information to applications of biochemicals, narcotics and essential oils. The details of the applications were briefly handled by the authors to increase their comprehensibility and feasibility. This guide should be certainly valuable to the novice, as well as to the experienced gas chromatography user who may not have the enough experience about the specific applications covered in this book. We believe this book will prove useful in most laboratories where modern gas chromatography is practiced.

\title{
How to reference
}

In order to correctly reference this scholarly work, feel free to copy and paste the following:

Petr Wojtowicz, Jitka Zrostlíková, Veronika Štastná, Eva Dostálová, Lenka Žídková, Per Bruheim and Tomáš Adam (2012). Comprehensive Two-Dimensional Gas Chromatography Coupled to Time-of-Flight Mass Spectrometry in Human Metabolomics, Gas Chromatography - Biochemicals, Narcotics and Essential Oils, Dr. Bekir Salih (Ed.), ISBN: 978-953-51-0295-3, InTech, Available from: http://www.intechopen.com/books/gaschromatography-biochemicals-narcotics-and-essential-oils/comprehensive-two-dimensional-gaschromatography-coupled-to-time-of-flight-mass-spectrometry-in-huma

\section{INTECH}

open science | open minds

\section{InTech Europe}

University Campus STeP Ri

Slavka Krautzeka 83/A

51000 Rijeka, Croatia

Phone: +385 (51) 770447

Fax: +385 (51) 686166

www.intechopen.com

\section{InTech China}

Unit 405, Office Block, Hotel Equatorial Shanghai

No.65, Yan An Road (West), Shanghai, 200040, China

中国上海市延安西路65号上海国际贵都大饭店办公楼 405 单元

Phone: +86-21-62489820

Fax: $+86-21-62489821$ 
(C) 2012 The Author(s). Licensee IntechOpen. This is an open access article distributed under the terms of the Creative Commons Attribution 3.0 License, which permits unrestricted use, distribution, and reproduction in any medium, provided the original work is properly cited. 